\title{
Critical Excerpts (Critiques) On Children’s Behavioral Development (CBD)
}

\section{Adel Masaud Agina*}

Department of Communication studies, University of Twente, Netherlands

\section{Introduction}

The seminal research regarding the contemporary Children's Behavioral Development (CBD), specifically Children's Private Speech (CPS) and Self-Regulation Learning (SRL), began in 1920s with the early work of Vygotsky and Jean Piaget 1950s. Since that time, the research came up with different and various outcomes associated with many and various critiques that the new research should take into account. Those critiques may lead the future work of CBD.

\section{Vygotskyian's vs. Piagetian Research}

Vygotsky viewed CPS as a function that directly connected to thought, problem solving, increases linearly with task difficulty and success, and represents a stage in the gradual internalisation of interpersonal linguistic exchanges whose final ontogenetic destination is inner speech or verbal thought. Vygotsky also believed that SelfRegulation Learning (SRL) is behavioral appearing after and as a result of regulation by others in a specific task and promoted by external regulators. Paradoxically, Piaget viewed CPS as egocentric or immature and believed that SRL is promoted by giving children extensive opportunities to make choices and decisions, to make rules by which they will regulate themselves. Piaget also believed that SRL is psychological presented from early infancy in the child's equilibration of actions and regulation by others does not have to come before selfregulation in a specific task. Piaget also argued that regulation by others hinders/devastate the development of self-regulation [1]. Recently, some researches [2-4], have briefly formulated what the previous work of SRL concluded as an empirical research question "how learners become strategic decision makers rather than strategic planner". This answer, however, remains challenged up to date.

\section{Some Theoretical Critiques}

Remarkably, the subsequent research, up to date, are fully guided either by Vygotsky [5-8] (e.g., Daugherty,) or Piaget [9] with only one major difference (if it can be seen and considered as a difference) is that, they used many alternatives to describe the concept of CPS such as self-verbalization [10] self-directed speech [11], and, most recently, self-talk [12] without explaining why those alternatives! Ironically, all those alternatives refer to the same phenomenon of children's overt speech to themselves during learning tasks as Vygotsky and Piaget already introduced! In this context, it is expected to see new terms to describe the concept of CPS but without any valuable or major changes that may lead, or at least inspire, the researchers to seriously think about a revolution in CBD given the fact that CPS and SRL still the based. In more specific language, what valuable will be added to the literature with new terms of the same phenomenon more than confusing the readers and the researcher as well?

\section{Some Experimental Critiques}

The research regarding CBD still involve the external regulators (teacher, experimenter, ... etc) to instruct and guide the participants, especially young children, before/during/after the experiment in which all of them still followed either Vygotsky's views or Piaget's views [1214]. On one hand, such external regulation, which is an actual form of social interaction, may negatively influence children to verbalize their actual regulation behavior and, therefore, direct their cognitive process towards undesirable verbalization/interaction. This external regulation, precisely, may cause children to divide their cognitive capacity between the present task and understating the external instructions, thereby forcing their cognitive process to act in different directions (i.e., towards a task focus process vs. an external focus process), which is socalled extraneous cognitive load that should be eliminated, or at least minimized, during the learning process [15]. On the other hand, the children's silence during the performance is also a cause for concern, especially for long time where the verbalization becomes invaluable and may lead to undesirable interaction as well. However, some researchers [16-17], have criticized the thinking aloud (TA) technique for the fact that TA and the limited capacity of memory hinder the participant's cognitive processes. Thus, affecting performance if the tasks involve a high cognitive load especially especially with the presence of the external regulator that, to a great extent, creates the problem of separating CPS and TA verbalization from the undesirable speech [10]. Given the fact that CPS and TA have the same mechanism of occurrences, the literature still lacks such a research that clearly show the difference between them and how can CPS be distinguished from TA?!

\section{Some Methodological Critiques}

Remarkably, TA has always considered as a high level of the participants' interaction because they are spontaneously talking to themselves and loudly thinking about their exact thoughts and feelings regarding the given task. In terms of human nature, however, this "thinking aloud", as a method of eliciting data, is not the same as "thinking aloud" in the everyday sense, which entails something other than sitting people down next to a tape recorder and asking them (actually, forced them) to talk/think loudly [18]. Stated differently, the pure thinking aloud, by nature, should spontaneously be occurred and without any Human-Human Interaction. In terms of Human-Media-Interaction, thinking aloud, based on its natural mechanism, can be considered as the spontaneous-interaction, which is completely differ from the compulsory-interaction, undesirable-interaction and inner-interaction. Despite the different and various outcomes concerning children's development, the research so far still relies on human as an external advisory/regulator/experimenter either before(How to train children to use the environment?), during (What shouldchildren do during the progression especially when they are seeking help instructions?), or after (How can children be able to answer the associated questionnaire without Human-Human-Interaction (HHI)?) given that the literature has been demonstrated that self-report measures do not necessarily give a reliable picture of the students' exact process they actually engage in [12]. Therefore, given the cognitive fact that the use of HHI with

${ }^{*}$ Corresponding author: Adel M. Agina, Professor, Department of Communication Studies, University of Twente, Netherlands, Tel: +31534893576/+218924887110; Fax: +31534891104; E-Mail: a.m.agina@utwente.nl.

Received January 15, 2015; Accepted January 16, 2015; Published January 25 2015

Citation: Agina AM (2015) Critical Excerpts (Critiques) On Children's Behavioral Development (CBD). J Psychol Abnorm Child 4: e104. doi:10.4172/23299525.1000e104

Copyright: @ 2015 Agina AM, et al. This is an open-access article distributed under the terms of the Creative Commons Attribution License, which permits unrestricted use, distribution, and reproduction in any medium, provided the original author and source are credited. 
children during the progression distorts, if not devastates, the natural occurrence of interaction, the given three practical processes "before", "during", and "after" remain the most significant challenge in the crossdisciplinary research of HMI and CBD especially with young users.

Regarding children's play, the research [19] reported that children's play often takes place at playgrounds. Playgrounds can take many forms ranging from the traditional school or park playground to novel interactive digital playgrounds. Digital playgrounds differ from traditional ones in that they are augmented with different kinds of technologies that can enhance engagement, entertainment, social interaction, physical exertion and immersion [20]. However, the literature, so far, still lacks researches that use such a computer-based environment that acts as a stand-alone to prevent any Human-HumanInteraction (HHI) either before, during, or after the progression to explore the extent the HMI can be used as close as possible to natural HHI when young children, especially at an early age, are conducted to be the participants.

\section{Some Critiques on Task Performance}

In the literature, many types of task feedback have been investigated by the researchers [21]. The most common types are Knowledge of performance $(K P)$, e.g., "you solved $90 \%$ of the problems correctly", Knowledge of result/response (KR), i.e., "your answer is correct/ incorrect", Knowledge of the correct response (KCR), i.e., provides the correct answer to the given task, Answer-until-correct (AUC), i.e., providing $\mathrm{KR}$ and offers the opportunity of further tries with the same task until the task is answered correctly, Multiple-try feedback $(M T F)$ provides KR and offers the opportunity of a limited number of further tries with the same task, and Elaborated feedback (EF) provides additional information besides KR or KCR. However, the question of whether young children, especially at an early age, are able to assimilate or even to understand the meaning of these types of feedback remains challenged. In terms of task performance, if the young user, on one hand, completes a task simply to receive a grade and the grade is not what he thought it should be, then he will be disappointed and provide less effort in the next task (i.e., less interaction will be showed/gained in the next task). On the other hand, the young user who completes a task to satisfy his curiosity and receives an average grade will provide more efforts in the next task (i.e., more interaction will be showed/ gained in the next task) to quench his curiosity or master a skill [22,23]. This conclusion, to a great extent, makes a 'collision/contradiction' with the fact that whether the young user's task precision (i.e., correct vs. incorrect answer) is an actual and real measurement of the higher vs. lowest interaction respectively. Based on that, choosing the level of the task complexity (simple vs. complex) is also under questioning!

\section{References}

1. Piaget $\mathrm{J}(1932 / 1965)$ the moral judgement of the child. London. Free Press.

2. Agina, A.M (2008) towards understanding self-organisation.How selfregulation contributes to self-organization? International Journal of Continuing Engineering Education and Life-Long Learning 18:366-379.

3. Butler DL (2002) Qualitative approaches to investigating self-regulated learning Contributions and challenges. Educational Psychologist 37:59-63.

4. Puustinen M, Pulkkinen L (2001) Models of self-regulated learning: A review. Scandinavian Journal of Educational Research 45.

5. Daugherty M, White C,Manning, B (1994) Relationships among private speech and creativity measurements of young children. Gifted Child Quarterly 38: 21-26.

6. Deniz CB (2004) Early childhood teachers' beliefs about, and self-reported practices toward, children's private speech. Dissertation Abstracts International Section A, Humanities and Social Sciences 64.
7. Ericsson K.A., \& Simon H.A (1993) Protocol analysis: Verbal reports as data $\left(2^{\text {nd }}\right.$ ed. $)$. Cambridge, MA: MIT Press.

8. Schunk DH (1986) Vicarious influences on self-efficacy for cognitive skill learning. Journal of Social and Clinical Psychology 4: 316-327.

9. DeVries R, Zan B (1992) Social processes in development: A constructivist view of Piaget, Vygotsky, and education. Paper presented at the annual meeting of the Jean Piaget Society, Montreal, Quebec, Canada.

10. Duncana RM, Cheyne JA (2002) Private speech in young adults task difficulty self-regulation, and psychological predication. Cognitive Development 16 889-906.

11. Winsler A, Fernyhough C, McClaren EM, Way E (2005) Private speech coding manual. Unpublished manuscript.George Mason University, Fairfax, VA, USA.

12. Winsler A, AbarB,Feder MA, SchunnCD,Rubio D A (2007) Private speech and executive functioning among high-functioning children with autistic spectrum disorders. Journal of Autism and Developmental Disorders, 37: 1617-1635.

13. FernyhoughC,Fradle, E (2005) Private speech on an executive task: Relations with task difficulty and task performance. Cognitive Development 20:103-120.

14. Tang CM, Bartsch K., Nunez N (2007) Young children's reports of when learning occurred. Journal of Experimental Child Psychology 97:149-164.

15. Sweller J (1998) Cognitive load during problem solving: Effects on learning Cognitive Science 12: 257-285.

16. Branch $\mathrm{JL}(2000)$ the trouble with think alouds: Generating data using verbal protocols. In A. Kublik (Ed.), Proceedings of the 28th annual conference of the canadian association for information science. Dimensions of a global information science, Canada.

17. Hoppmann TK (2009) Examining the "point of frustration": The think-aloud method applied to online search tasks. Quality and Quantity 23:211-224.

18. Jääskeläinen R (1999) Tapping the process: An explorative study of the cognitive and affective factors involved in translating. Joensuu: University of Joensuu.

19. Moreno A.,vanDelden R, Reidsma D, Poppe R, Heylen D (2012) An Annotation Scheme for Social Interaction in Digital Playgrounds. IFIP International Federation for Information Processing 2012.

20. Bichard JP, Waern A (2008) Pervasive play, immersion and story: designing interference. In: Proceedings of the International Conference on Digital Interactive Media in Entertainment and Arts, DIMEA 2008, New York, NY, USA, pp. 10-17.

21. John Hattie J, Timperley $H$ (2007) The power of feedback. Review of Educational Research 77: 81-112.

22. Gottfried AE, Fleming J,Gottfried AW (1994)Role of parental motivationa practices in children's academic intrinsic motivation and achievement. Journal of Educational Psychology 86: 104-113.

23. Seitinger S (2006) An ecological approach to children's playground props. In Proceedings of the Conference on Interaction Design and Children, IDC 2006 New York, USA, pp. 117-120. 